\title{
O impacto do luto para os profissionais de enfermagem da unidade de emergência
}

\author{
The impact of grief on emergency unit nursing professionals \\ El impacto del duelo en los profesionales de enfermería de las unidades de emergencia
}

Recebido: 18/10/2021 | Revisado: 27/10/2021 | Aceito: 29/10/2021 | Publicado: 01/11/2021

Luana Ferreira Gomes Dias

ORCID: https://orcid.org/0000-0002-2015-3392 Centro Universitário Dinâmica das Cataratas, Brasil E-mail: luana_gomes1212@hotmail.com

Wesley Martins

ORCID: https://orcid.org/0000-0003-1083-9515 Centro Universitário Dinâmica das Cataratas, Brasil E-mail: wesley.martins@udc.edu.br

\begin{abstract}
Resumo
Este estudo teve como objetivo identificar os impactos vivenciados pelos profissionais de enfermagem diante do luto após a morte de pacientes na unidade de emergência. Trata-se de uma pesquisa descritiva e exploratória, de caráter qualitativo, através de coleta de dados com 17 profissionais de enfermagem que atuam na unidade de emergência de um hospital municipal na cidade de Foz do Iguaçu. Após a transcrição das entrevistas, os resultados foram analisados a partir da técnica de Análise de Conteúdo de Laurence Bardin, (2016). Assim, os dados foram agrupados em três categorias: entendimento do processo de morte, sentimentos diante da morte de pacientes e enfrentamento do processo de luto. Assim, através deste estudo, identificou-se que os profissionais sofrem impactos com a morte de pacientes, ocasionando assim sentimentos de tristeza, choro, e ainda sentimento de impotência para aceitação da perda de um ente querido. Sendo assim, conclui-se que é essencial a inclusão do assunto processo de morte e luto na educação continuada a fim de preparar os profissionais de enfermagem a lidar com o processo de luto após a perda de pacientes, especialmente na unidade de emergência, onde a ocorrência de óbitos é maior.
\end{abstract}

Palavras-chave: Enfermagem; Emergência; Sentimentos; Morte; Luto.

\begin{abstract}
This study aimed to identify the impacts experienced by nursing professionals in the face of grief after the death of patients in the emergency unit. This is a descriptive and exploratory research, qualitative in nature, through data collection with 17 nursing professionals who work in the emergency unit of a municipal hospital in the city of Foz do Iguaçu. After transcribing the interviews, the results were analyzed using the Content Analysis technique by Laurence Bardin (2016). Thus, data were grouped into three categories: understanding the death process, feelings about the death of patients and coping with the grieving process. Thus, through this study, it was identified that professionals suffer impacts with the death of patients, thus causing feelings of sadness, crying, and even a feeling of impotence to accept the loss of a loved one. Therefore, it is concluded that it is essential to include the subject of death and grief in continuing education in order to prepare nursing professionals to deal with the grieving process after the loss of patients, especially in the emergency unit, where the occurrence of deaths is higher.
\end{abstract}

Keywords: Nursing; Emergency; Feelings; Death; Grief.

\section{Resumen}

Este estudio tuvo como objetivo identificar los impactos que experimentan los profesionales de enfermería ante el duelo tras la muerte de los pacientes en la unidad de urgencias. Se trata de una investigación descriptiva y exploratoria, de carácter cualitativo, a través de la recolección de datos con 17 profesionales de enfermería que laboran en la unidad de emergencia de un hospital municipal de la ciudad de Foz do Iguaçu. Tras la transcripción de las entrevistas, los resultados fueron analizados mediante la técnica de Análisis de Contenido de Laurence Bardin (2016). Así, los datos se agruparon en tres categorías: comprensión del proceso de muerte, sentimientos sobre la muerte de los pacientes y afrontamiento del proceso de duelo. Así, a través de este estudio, se identificó que los profesionales sufren impactos con la muerte de los pacientes, provocando sentimientos de tristeza, llanto e incluso un sentimiento de impotencia para aceptar la pérdida de un ser querido. Por tanto, se concluye que es fundamental incluir el tema de la muerte y el duelo en la educación continua con el fin de preparar a los profesionales de enfermería para afrontar el proceso de duelo tras la pérdida de los pacientes, especialmente en la unidad de urgencias, donde se produce la ocurrencia de muertes. más alto.

Palabras clave: Enfermería; Emergencia; Sentimientos; Muerte; Dolor. 


\section{Introdução}

A morte envolve diversos significados, em diferentes áreas de conhecimento como a ciência, religião e cultura. É um processo natural e inevitável, sendo o término de um ciclo de vida. Mesmo assim, ainda é um tabu e pouco se houve falar, pois ocasiona impactos emocionais, devido a separação e perda de um familiar ou amigo (Lacerda et al., 2016).

Segundo Arantes (2016), o processo de luto tem início após a morte de um ente querido, ou seja, após o rompimento de um vínculo intenso, e muitas pessoas não conseguem lidar com a dor e sofrimento da perda, e assim, procuram evitar o sofrimento através do uso indevido de antidepressivos e calmantes, ocasionando uma anestesia emocional.

Embora o vínculo nem sempre esteja consolidado, Baldissera et al. (2018) mencionam que os profissionais de saúde se sentem despreparados para lidar com a morte de pacientes, estando presente sentimentos de frustação e tristeza. Além disso, muitos profissionais sentem que não receberam qualificação necessária durante a graduação.

Nesse sentido, vale ressaltar que os profissionais têm mais dificuldade para lidar com a morte de pacientes pediátricos, na qual normalmente são vistos como uma tragédia, visto que a criança ainda tem muito a viver e que um ciclo de vida foi interrompido. Em contrapartida, a morte de idosos tem uma melhor aceitação, pois o idoso já percorreu sua trajetória de vida e nesse caso a morte é vista como um descanso (Bosco, 2008).

De acordo com um estudo realizado em uma Unidade Hospitalar de Pronto Atendimento no estado de São Paulo, em 2018, os profissionais de enfermagem relataram diversos sentimentos, dentre eles os de tristeza, sofrimento e impotência, devido a impossibilidade de salvar a vida dos pacientes, ocasionando ainda, sentimento de culpa (Machado, et al., 2018).

Ainda de acordo com o autor supracitado, além do estresse emocional devido a perca dos pacientes, os profissionais precisam lidar com o estresse da demanda do trabalho, que muitas vezes não estão preparados, refletindo na assistência dos cuidados e no seu estado emocional.

Diante do exposto, esse estudo tem como objetivo identificar os impactos vivenciados pelos profissionais de enfermagem diante do luto após a morte de pacientes na unidade de emergência.

\section{Metodologia}

Trata-se de uma pesquisa descritiva e exploratória, de caráter qualitativo, realizado em um hospital público, referência no atendimento de emergência aos pacientes adultos e pediátricos do município de Foz do Iguaçu-PR. A análise dos dados foi realizada seguindo as diretrizes da Análise de Conteúdo, proposto por Laurence Bardin (2016).

A coleta de dados ocorreu com os profissionais da unidade de emergência durante o mês de julho de 2021 e se deu através de um instrumento composto por duas partes: a primeira, com dados de identificação dos participantes (sexo, idade, formação acadêmica, tempo de formação, tempo de atuação no setor de emergência, realização de cursos de extensão sobre a temática do processo de morte e/ou luto); e a segunda, com os seguintes assuntos norteadores: processos de morte, sentimentos de luto, capacitação do cuidado emocional.

Participaram da pesquisa 17 profissionais de enfermagem, entre eles, 13 técnicos de enfermagem e 4 enfermeiros, que atuam na unidade de emergência. Um dos conceitos utilizados para a seleção dos sujeitos de pesquisa foi o critério de representatividade com o objetivo da pesquisa.

Nesse sentido, foi necessário estabelecer critérios de inclusão e exclusão, para buscar os sujeitos que dispõem os conceitos que os investigadores desejavam explorar e avaliar. Desse modo, foi estabelecido o seguinte critério de inclusão: profissionais de enfermagem efetivos que atuam no setor de emergência com tempo mínimo de seis meses.

A fim de manter o sigilo e o anonimato da identificação, os participantes receberam um código de identificação, constituído pela seguinte forma: E (entrevista) + número em algarismo em ordem crescente, conforme a sequência em que as entrevistas foram realizadas. 
A pesquisa foi realizada na data e horário conforme disponibilidade dos participantes. O local escolhido foi a sala de triagem, um ambiente reservado e de fácil acesso a todos, previamente autorizada pela equipe responsável. A duração da entrevista não foi predeterminada, dependendo assim de cada participante, todavia, o tempo médio de cada entrevista foi de 10 minutos.

Bardin (2016) em seu método, pressupõe a análise de conteúdo em três passos: pré-análise, exploração do material e tratamento dos resultados, inferência e interpretação. As entrevistas foram transcritas na íntegra a fim de evitar a perda dos detalhes importantes. Realizou-se a leitura flutuante diversas vezes e a organização do material, a fim de se envolver com os relatos dos participantes e não perder nenhum dado pertinente ao objetivo do estudo.

Após, foi realizado a classificação em frases ou palavras que abrangiam as ideais centrais do objetivo. Ao térmico desta organização, conseguiu-se organizar vários tópicos, os quais foram agrupados por semelhança. E então, a partir da organização e categorização das entrevistas, iniciou-se a análise das categorias e discussão das mesmas.

Este estudo se iniciou após a aprovação do Comitê de Ética em Pesquisa Envolvendo Seres Humanos (CEP), vinculado ao Conselho Nacional de Ética em Pesquisa (CONEP), respeitando todas as questões éticas e legais regidos nas resoluções CNS 466/2012 e CNS 510/2015, mantendo a integridade física e emocional, a dignidade e os interesses de todos os envolvidos na pesquisa. O projeto foi submetido ao CEP e aprovado sob Parecer $\mathrm{n}^{\circ} 4.824 .29$.

\section{Resultados e Discussão}

A Tabela 1 apresenta os dados de caracterização dos participantes da pesquisa, tais como o sexo, a idade, o estado civil, a formação e o tempo de trabalho. 
Tabela 1. Caracterização dos participantes da pesquisa quanto ao sexo, idade, estado civil, formação e tempo de trabalho, Foz do Iguaçu, Paraná, Brasil.

\begin{tabular}{|c|c|c|}
\hline VARIÁVEIS & $\mathbf{N}$ & $\%$ \\
\hline \multicolumn{3}{|l|}{ SEXO } \\
\hline Feminino & 13 & 76,5 \\
\hline Masculino & 4 & 23,5 \\
\hline \multicolumn{3}{|l|}{ IDADE } \\
\hline 30 a 40 & 9 & 52,9 \\
\hline 41 a 50 & 5 & 29,4 \\
\hline 51 a 60 & 3 & 17,7 \\
\hline \multicolumn{3}{|l|}{ ESTADO CIVIL } \\
\hline Solteiro (a) & 4 & 23,5 \\
\hline Casado (a) & 8 & 47,1 \\
\hline Divorciado (a) & 5 & 29,4 \\
\hline \multicolumn{3}{|l|}{ FORMAÇÃO } \\
\hline Técnico em Enfermagem & 13 & 76,5 \\
\hline Enfermeiro & 4 & 23,5 \\
\hline \multicolumn{3}{|l|}{ TEMPO DE TRABALHO } \\
\hline 1 a 10 anos & 12 & 70,6 \\
\hline 11 a 20 anos & 4 & 23,5 \\
\hline 21 a 30 anos & 1 & 5,9 \\
\hline
\end{tabular}

Fonte: Instrumento de coleta de dados.

Quanto ao sexo, $13(76,5 \%)$ participantes são do sexo feminino. Em relação a faixa etária, 9 (52,9\%) têm entre 31 a 40 anos. Sobre o estado civil prevaleceu-se profissionais casados, $8(47,1 \%)$. E referente a formação, se destacou o técnico em enfermagem com $12(70,6 \%)$ entrevistados.

Nota-se uma semelhança com os dados obtidos no trabalho de Machado (2018), realizado com 7 participantes, onde em sua pesquisa $5(71,4 \%)$ são do sexo feminino, mostrando assim que o sexo feminino prevalece entre os profissionais de enfermagem. Em relação faixa etária, também há uma compatibilidade na porcentagem dos dados, pois sua pesquisa resultou que $6(85,7 \%)$ dos profissionais entrevistados têm entre 31 a 50 anos. E neste estudo, se realizarmos a junção dos dois subitens: 30 a 40 anos e 41 a 50 anos, obtemos o resultado de $14(82,3 \%)$.

A partir da análise de dados, foram reagrupados os tópicos em três temais centrais a ser discutido, sendo eles: entendimento do processo de morte; sentimentos diante da morte de pacientes; e enfrentamento do processo de luto.

\subsection{Entendimento do Processo de Morte}

Nos questionamentos referentes ao entendimento do processo de morte, os profissionais mencionaram diversas definições, entre as quais se destaca a compreensão da morte em duas formas divergentes: um processo doloroso, ou seja, de difícil aceitação, e um processo natural da existência humana. 


\subsubsection{Processo doloroso}

O processo de morte não é facilmente compreendido pela maioria das pessoas, e para os profissionais de saúde a morte faz parte do seu cotidiano, ocasionando assim diversos sentimentos e reações.

O processo doloroso do enfrentamento de morte pode ser analisado através das narrações dos participantes, onde é possível observar a dificuldade dos profissionais em compreender e falar sobre o processo de morte:

"Olha pra mim é muito dificil, cada morte pra mim é dolorida." (E6)

"Aahh, é um processo que sempre é difícil de lidar né, porque a gente sempre espera o tratamento e a melhora do paciente. [...] Então esse enfrentamento é bem dificil." (E8)

"Aahh é muito doloroso, a gente se coloca no lugar da família, eu me coloco muito em lugar da família. (E14)

"Doloroso, principalmente pra família em si, é sempre dificil pra gente dá notícia pra família, você fazer de tudo pro paciente, e no fim não conseguir." (E16)

"É uma coisa dolorosa né, pra família, pra nós profissionais que está perdendo alguém que está tentando salvar, então nesses anos todos é dificil, é triste perder um paciente." (E17)

Baldissera et al. (2018) ainda relata que os profissionais de enfermagem possuem dificuldades para falar sobre a morte, principalmente quando o assunto é sobre a perda de pacientes que ficaram internados, pois além de lidar com o paciente que está com o estado de saúde instável, precisam lidar com a família, e as vezes cria-se um vínculo afetivo.

No entanto, para Bosco (2008) os profissionais têm mais dificuldade para lidar com a morte, quando envolve a perda de pacientes pediátricos, onde é visto como uma tragédia, que a criança ainda tem muito a viver e que um ciclo de vida foi interrompido.

Neste sentido, a morte durante a infância é vista como um evento precoce e de injustiça, pois seguindo a analogia da vida, espera-se que a criança cresça e desfrute da infância até chegar à vida adulta, e posteriormente a velhice, e então esperar a morte, como finitude do processo viver (Argenta, 2008).

“[...] Quando morre esses pacientes mais jovens a gente fica meio que se questionando porque nem sempre para nós humanos não é normal alguém jovem morrer de algumas coisas traumáticas, não é uma doença... Mais complicadinho aceitar quando é jovem ou criança." (E1)

“Aahh... É muito triste... Quando a gente perde um paciente jovem e criança é um choque pra gente, principalmente pra mim, dependendo o dia, começou o plantão e aconteceu, parece que o dia não rende... Vai desabando o dia." (E2)

Sendo assim, podemos confirmar que a dificuldade de enfrentamento do processo de morte de crianças e adolescente é mais evidenciada, pois esse acontecimento é relacionado a uma interrupção do processo natural da vida, ocasionando sofrimento aos profissionais.

\subsubsection{Processo natural}

Em contrapartida, muitos profissionais associaram o processo de morte a um processo natural, ou seja, um processo aceitável, e que será vivenciado por todos, sem exceção. Neste sentido, compreender a morte como algo natural, é aceitar que a vida tem um começo, meio e fim.

"Profissionalmente falando eu trato como algo natural... um processo natural." (E1)

"Agora pra mim o processo de morte é um acontecimento normal né, eu falo que a morte anda no nosso lado sempre, sempre está com a gente [...]" (E5)

"Inevitável... Por mais que a gente tente minimizar, muitas vezes evitar, é uma coisa... inevitável. (E7)

"É um processo natural. Todo mundo precisa passar por isso" (E9) 
"Hoje em dia, entendo como uma situação normal de vida no pronto socorro, a cada dia" (E10)

"Como algo natural, faz parte, assim como a vida, todos os mecanismos fisiológicos e psíquicos que é inerente a vida do ser humano, a morte também faz parte do ciclo natural, claro que tem as exceções né, como os acidentes, ainda sim faz parte de todo o processo natural." (E12)

Sandoval (2020) realizou um estudo aplicando um questionário sobre o significado da morte e o processo morrer, e assim, nos resultados do seu estudo, demonstrou que o entendimento da morte como um evento natural do processo de vida se destacou entre as ideias mencionas pelos participantes.

No entanto, para alguns profissionais o significado da morte pode estar relacionado a um processo natural da vida somente quando associada a pessoas idosas, pois assim é compreendida como consequência da vida humana, ou seja, o idoso passou pelas fases do ciclo de vida e assim durante a velhice, a morte se torna um evento esperado.

De acordo com Gonçalves e Simões (2019) a morte ocorre em pessoas idosas se torna mais tolerável para os profissionais, devido ao ciclo do desenvolvimento humano, nascer, crescer reproduzir e morrer. Então, na velhice, o ser humano conclui a sua história, e isto desperta nos profissionais sentimentos de processo de finitude da sua vivência.

“Depende... [...] Quando é alguém mais velho, um caso clínico de prognóstico ruim, é mais natural." (E1)

"Depende da idade do paciente, paciente de mais idade entendo como uma ordem natural das coisas né... da vida. $[\ldots] "(E 4)$

Nas palavras de Benedetti, 2013 o significado da morte pode estar relacionado a um processo natural da vida, quando envolve a perda de paciente idosos ou portadores de doenças crônicas e que ainda não houve a formação de vínculo afetivo, desse modo é entendida como consequência do ciclo da vida humana.

Sendo assim, podemos confirmar que os profissionais de saúde compreendem de forma afetiva a morte de pacientes com doenças crônicas, ou seja, fase considerada final de vida, pois, conforme relata Perboni et al. (2018) "quando o paciente apresenta situações de sofrimento, sem qualidade de vida, os profissionais aceitam de forma mais branda a morte".

\subsection{Sentimentos diante da morte de pacientes}

Nessa categoria, os participantes da pesquisa relataram suas experiencias a respeito dos sentimentos diante da morte de paciente. Pode-se constatar três formas de enfrentamento: tristeza, perda e choro; negação; dever cumprido e respeito ao paciente.

\subsubsection{Tristeza, perda e choro}

O processo de morte está inserido no ciclo natural da vida, onde é visto pela sociedade como um evento que vai em sentido contrário, devido aos sentimentos de tristeza e perda, e ainda envolve sentimento de impotência para aceitação da perda de um ente querido (Baldissera et al., 2018).

A morte ocasiona impactos na vida das pessoas, no entanto, a maneira como cada indivíduo compreende o processo de morte e como relaciona este evento com suas vivências pessoas e profissionais, distingue o modo do enfrentamento deste processo (Kuster \& Bisogno, 2010).

Alguns profissionais desenvolvem sentimentos de tristeza, frustração, culpa e ainda apresentam crises de choro, conforme relatos abaixo:

"É triste... A gente faz de tudo para o paciente sobreviver, lutamos... Ai chega àquela hora que vai... Eu me sinto triste... [...] principalmente criança, criança eu choro... dói muito... Criança é pior.” (E3) 
"É triste... Tem momento complicados, a gente interage com o paciente, com a família... Quando você vai dar o aviso lá pra esposa, pro filho... tem momento que a gente dá um baque” (E13)

"Falando de mim mesma... aahh é um momento difícil pra gente, no começo foi muito difícil pra mim porque quando entrava um paciente em óbito, acho que eu chorava mais que a família. [...]” (E14)

"É triste né... Cada paciente é diferente do outro, o sentimento é diferente." (E15)

Souza et al. (2020) afirma que os profissionais de enfermagem possuem um papel fundamental diante do processo de morte, pois o profissional atua no cuidado ao paciente, o que ocasiona uma proximidade, e assim, diante da perda, pode causarlhe impactos emocionais como sentimentos de frustação, raiva e tristeza por não conseguir evitar a morte deste paciente.

“[...] sempre é um sentimento doloroso, de perda, é triste, é uma vida que tá indo, e você pensa muito na familia, porque aquela pessoa ela é o amor de alguém, ela é importante pra alguém.” (E16)

Esses sentimentos diante da perda de pacientes, também é comprovado por Faria e Figueiredo (2017) onde em sua pesquisa descreve que os profissionais de saúde demonstram sentimentos de tristeza e impotência diante da vivência do processo de morte nas instituições hospitalares.

Gregório (2018) aponta que o profissional de enfermagem possui sentimentos e emoções, e por isso quando vivencia a morte de um paciente expressa sentimentos como frustação, revolta, culpa e ansiedade. Porém, a maneira como o profissional enfrenta este processo depende da estabilidade emocional e sua atitude frente a morte.

Conforme descreve Argenta, (2008) “os profissionais de saúde são preparados para cuidar e preservar a vida, por conseguinte, a morte representa, em vários momentos, sentimento de fracasso, inabilidade e, até mesmo, incapacidade.”

\subsubsection{Negação}

Vale ressaltar ainda, que nas entrevistas foi mencionada o sentimento de negação, no qual, é muita utilizada como um mecanismo no enfrentamento do processo de morte. Este mecanismo fortalece um paradoxo, onde os profissionais enfrentam diariamente a morte de pacientes, no entanto, se recusam a aceitá-la como parte do ciclo da vida humana.

"Na verdade, a gente muitas vezes tem que bloquear, porque a gente não pode deixar interferir no pessoal. Mas tem o pesar... a gente sente, só não pode deixar interferir na vida pessoal porque aqui a gente está como profissional, e não pode deixar aflorar os sentimentos. ” (E8)

“Aahh a gente fica chocado né, não é fácil aceitar a morte, eu não aceito a morte.” (E11)

Nota-se que os relatos acima nos revelam atitudes de negação da finitude da vida, pois a morte ainda é vista como um fracasso. Os profissionais tem como foco restabelecer a saúde dos pacientes, e assim, quando ocorre a morte, os profissionais são dominados por sentimento de culpa, incapacidade e angústia, já que estão preparados apenas para combater a morte e não para aceita-la como ocorrência inevitável.

Santos (2016) em seu estudo, revela resultado similar, descrevendo que "outra forma de enfrentamento é a atitude de negação ou evitar pensar, refletir a respeito do sofrimento e morte no trabalho", sendo assim, este sentimento é utilizado como uma válvula de escape, para que a angústia provocada pela morte de paciente não alcance seus sentimentos e emoções, ocasionando desequilíbrio a saúde mental.

Ainda neste sentido, podemos confirmar a presença deste sentimento nos profissionais, a partir do estudo realizado por Ferreira et al. (2012) que descreve que os profissionais evitam criar vínculo emocional com os pacientes, para não desenvolver ansiedade e sentimentos de tristeza, e assim, amenizar o sofrimento após a morte do paciente. 


\subsection{3 "Dever cumprido e respeito ao paciente"}

Alguns relatos de profissionais indicaram sentimentos divergentes até então, no qual relataram sentimentos de "dever cumprido" e "respeito" pelo paciente:

"Olha meu sentimento normalmente, na maioria das vezes é de eu fiz a minha parte, no sentindo de o que eu puder fazer para que promova a vida daquele paciente eu e a minha equipe a gente faz. Nunca saí daqui do pronto socorro com sentimento que não fiz nada sabe..." (E12)

Assim, vale ressaltar que o relato do profissional acima demonstra sentimento pós morte como dever cumprido, ou seja, associou a morte como um processo de finitude da vida, onde enquanto o paciente estava vivo foi ofertado toda a atenção e profissionalismo afim de restaurar a saúde do paciente. No entanto, não se pode evitar o óbito, e então prevaleceu o sentimento de "eu fiz a minha parte".

Nesse sentindo, outro profissional relatou o respeito como sentimento de pós morte. Respeito com o corpo, e respeito ao familiar, no quesito de informar o óbito do paciente aos familiares, alegando assim que os pacientes merecem respeito mesmo após o óbito, pois não é apenas um corpo, é um ser humano que finalizou uma história de vida:

"Na minha situação é o respeito, é o que eu priorizo para o paciente e principalmente para o familiar. Eu costumo ser direto na informação, mas principalmente ter respeito no processo de passar informação, isso é fundamental, porque a gente não sabe como o familiar vai receber essa notícia e o respeito ao paciente também né, não é só um corpo né, tem toda uma história." (E8)

\subsection{Enfrentamento do processo de luto}

Machado et al. (2018) descreve que a diferença básica do enfrentamento do processo de morte entre os profissionais de saúde e os leigos, é que a morte está presente diariamente na vida do profissional, e assim torna-se sua companheira de trabalho. Mesmo que a morte faça parte do cotidiano, não isenta o profissional de enfrentar sentimentos de luto.

Nas palavras de Mendes et al. (2018) “a morte diz respeito àquele que se foi, já o luto é o processo experienciado por quem fica”, ou seja, o luto é um processo que acontece após o rompimento de um vínculo significativo (Arantes, 2016).

Por isso, Trevisano et al. (2019), descrevem o luto como "uma reação emocional a uma perda significativa, um processo natural e a recuperação diante da perda. É visto como um processo mental no qual o equilíbrio físico é restabelecido após a perda de um ente querido."

O luto é uma experiência única e individual, ou seja, cada indivíduo enfrenta de sua maneira esse momento de dor, e todos que cercam o enlutado deve respeitar esse momento. Esse momento envolve um complexo de sentimentos, e o indivíduo enlutado pode apresentar diversos sinais e sintomas tais como: ansiedade, culpa, raiva, solidão, choro, perda de apetite, depressão, fadiga, entre outros (Zorzo, 2004).

Durante a entrevista, houve um questionamento sobre como lidar com o luto após a morte de pacientes. A partir dos relatos, é possível observar a dificuldade dos profissionais em lidar com o processo de finitude da vida:

"Aaah, a gente procura não levar esse luto pra casa né, não pensar no que aconteceu, fora daqui, porque quando você está aqui você não consegue esquecer, e a gente fica 12 horas aqui né... É bem complicado né... Eu procuro não levar o máximo... o mínimo de lembrar das coisas que acontece aqui." (E2)

"Não sei dizer... É muito difícil, a gente fica bastante triste né... você acaba criando um vínculo ali." (E4)

"Aahh eu tento esquecer, eu tento colocar uma barreira na minha cabeça, principalmente quando eu vou pra casa, pra não levar junto comigo o que eu vejo aqui. Tem vezes que é mais dificil." (E5) 
Com base nos depoimentos, podemos observar que os profissionais, em geral, se sentem despreparados para lidar com a morte no ambiente hospitalar, e assim, como fuga dos sentimentos se afastam e tentam esquecer esse momento vivenciado, criando assim, barreiras dos sentimentos de luto.

Neste sentido, podemos mencionar o estudo realizado por Soares et al. (2021) com estagiários de enfermagem, onde comprovou que estes não possuem preparo emocional para lidar com o tema morte, e por isso utilizam mecanismos de defesas como estratégias emocionais frente ao luto.

Vale ressaltar ainda referente ao estudo acima que, $50 \%$ dos participantes relataram que o mecanismo de defesa utilizado é a aceitação que fizeram o que estava ao seu alcance e que a promoção do conforto ao doente ameniza o sentimento de impotência após a morte do paciente.

\section{Considerações Finais}

Na perspectiva dos profissionais de enfermagem que atuam na unidade de emergência, a morte faz parte do seu dia a dia e cada profissional possui seu jeito de lidar com esse processo. Ficou evidente que os sentimentos do processo de morte envolvem alguns fatores determinantes, como a idade do paciente, o vínculo afetivo com o paciente e familiar e também o modo como cada profissional compreende o processo de morte.

Os profissionais possuem um papel fundamental diante do processo de morte, pois o profissional atua no cuidado ao doente, criando assim um vínculo afetivo, tanto com os pacientes quanto com os familiares, e assim, quando ocorre a morte do paciente, ocasiona impactos emocionais.

A análise de dados demonstra que os profissionais, ao vivenciarem a morte de seus pacientes, apresentam diversos sentimentos: tristeza, frustação, dor, choro e angústia. Logo, podemos concluir que os profissionais de enfermagem que trabalham na unidade de emergência não estão preparados para lidar com estes eventos, pois estes têm como foco a restauração da vida, e quando o paciente vai a óbito, os profissionais expressam sentimento de culpa e incapacidade.

Percebe-se que há necessidade de inclusão do tema do processo de morte e processo de luto na educação permanente nas instituições hospitalares, principalmente setores de emergência, onde há o cuidado de paciente instáveis, com o objetivo de preparar os profissionais de saúde para lidar com o luto no ambiente hospitalar e implementar medidas preventivas, a fim de garantir melhorias na qualidade de vida dos profissionais e qualidade de serviços prestados.

\section{Referências}

Arantes, A. C. Q. (2016). A morte é um dia que vale a pena viver. Rio de Janeiro: Casa da palavra.

Argenta, C., Feldens, J., Hildebrandt, L., Leite, M., \& Sand, I. (2008). A morte em setor de emergência e seus reflexos na equipe de saúde: uma revisão bibliográfica. Cogitare Enfermagem, 13(2).

Baldissera, A., Bellini, L., Ferrer, A., Barreto, M., Coimbra, J., \& Marcon, S. (2018). Perspectiva de profissionais de enfermagem sobre a morte na emergência. Revista de Enfermagem UFPE on line, 12(5), 1317-1324.

Bardin, L. 2016. Análise de conteúdo / tradução Luiz Antero Reto, Augusto Pinheiro, São Paulo: Edições 70.

Benedetti, G. M. S., Oliveira, K., Oliveira, W. T., Sales, C. A., \& Ferreira, P. C. (2013). Significado do processo morte/morrer para os acadêmicos ingressantes no curso de enfermagem. Rev. gaúch. enferm; 34(1):173-179.

Bosco, A. G. (2008). Perda e luto na equipe de enfermagem do centro cirúrgico de urgência e emergência. Dissertação de Mestrado, Escola de Enfermagem de Ribeirão Preto, Universidade de São Paulo, Ribeirão Preto. 10.11606/D.22.2008.tde-03092008-105509.

Faria, S. S., \& Figuereido, J. S. (2017). Aspectos emocionais do luto e da morte em profissionais da equipe de saúde no contexto hospitalar. Psicologia Hospitalar, $15(1), 44-66$.

Ferreira, A. P. A., Sabatke, C. E., Montezeli, J. H., \& Venturi K. K. (2012). Vivência da morte de vítimas de trauma em pronto-socorro: estudo descritivo. Online braz. j. nurs. (Online);11(1). 
Gonçalves, J. R., \& Simões, J. R. S. (2019). A percepção do enfermeiro no lidar com a morte durante a assistência. Revista JRG De Estudos Acadêmicos, 2(5), $166-182$.

Gregório, A. I. A. (2018). Os Enfermeiros e a vivência da morte em jovens dos 18-25 anos no Serviço de Urgência. Universidade Fernando Pessoa, Faculdade de Ciências da Saúde. http://hdl.handle.net/10284/7064.

Kuster, D. K., \& Bisogno, S. B. C. (2010). A percepção do enfermeiro diante da morte dos pacientes. Disc. Scientia. Série: Ciências da Saúde, 11(1), 9-24.

Lacerda, C. A., Camboim, F. E. F., Camboim, J. C. A., Nunes, E. M., Bezerra, A. L. D., \& Souza, M. N. A. (2016). O lidar com a morte em unidade de terapia intensiva: dificuldades relatadas por enfermeiros. C\&D-Revista Eletrônica da Fainor, 9(2), 173-184.

Machado, N. L. M., Zanoti, M. D. U, Perego, M. G., \& Araújo, D. C. M. (2018). O enfermeiro diante da ocorrência de morte em ambiente de urgência e emergência. CuidArte Enfermagem, 12(1), 23-29.

Mendes, D. T., Santos, E. K. R., \& Marback, R. F. (2018). É preciso falar sobre a morte: equipe de saúde e luto no hospital geral. XVI SEPA - Seminário Estudantil de Produção Acadêmica, UNIFACS. http://www.revistas.unifacs.br/index.php/sepa.

Sandoval, S. A., Vargas, M. A. O., Schneider, D. G., Magalhães, A. L. P., Brehmer, L.C. F., \& Zilli, F. (2020). Morte e morrer no hospital: uma visão social, espiritual e ética dos alunos. Esc. Anna Nery (24) 3.

Santos, J. L., Corral-Mulato, S., Villela-Bueno, S. M., \& Carmo-Cruz-Robazzi, M. L. (2016). Sentimentos de enfermeiros confrontados com a morte: prazer e sofrimento sob a ótica da psicodinâmica de Dejours. Investigación y Educación en Enfermería, 34(3), 511-517.

Soares, A. N., Gonçalves, F. T. D., Melo, K. C., Silva, W. C. D., Silva, C. O., Hernandes, L. F., \& Alves, T. D. S. (2021). O trabalho de luto e o trabalho com o luto: Percepção de estagiários de enfermagem sobre a morte e o morrer junto a pacientes hospitalizados. Research, Society and Development, 10(2).

Siqueira-Perboni, J., Zilli, F., \& Griebeler-Oliveira, S. (2019). Profissionais de saúde e o processo de morte e morrer dos pacientes: uma revisão integrativa. Persona Y Bioética, 22(2), 288-302.

Souza, S. A. N., Nogueira, S. C. da R., Santos, W. L. dos., \& Santos, A. L. M. dos. (2020). Óbito e luto: os desafios encontrados pela equipe de enfermagem. Revista JRG De Estudos Acadêmicos, 3(6), 36-43.

Trevisano, R. G., Almeida, J. V., \& Barreto, C. A., (2019). O olhar da enfermagem no processo de luto. Revista Saúde em Foco-Edição nº 11.

Zorzo, J. C. C. (2004). O processo de morte e morrer da criança e do adolescente: vivências dos profissionais de enfermagem. Dissertação de Mestrado, Escola de Enfermagem de Ribeirão Preto, Universidade de São Paulo, Ribeirão Preto. 10.11606/D.22.2004.tde-07072004-114012 